\title{
Efektivitas Penggunaan
}

Media Pembelajaran Permainan Ludo Kimia Berbasis Chemo-Edutainment (CET) pada Materi Struktur Atom terhadap Hasil Belajar Siswa Kelas X SMA N 3 Padang

\section{The Effectivity an Instructional Media of Ludo Game Based on Chemo-Edutainment (CET) for Atomic Structure Toward $1^{\text {st }}$ Grade Students Achievement from SMA N 3 Padang}

\author{
A R Fadillah ${ }^{1}$ and Iswendi ${ }^{*}$ \\ ${ }^{1}$ Pendidikan Kimia, Universitas Negeri Padang, Jl. Prof. Dr. Hamka, Air Tawar Barat, \\ Padang Utara, Sumatera Barat, Indonesia 25171 \\ *iswendi@fmipa.unp.ac.id
}

\section{ARTICLE INFO}

Received 16 October 2019

Revised 20 October 2019

Published 21 October 2019

\begin{abstract}
This study aimed to reveal the effectivity of the use an instructional media of ludo game based on Chemo Edutainment for Atomic Structure toward 10th students achievement. The type of this research was Quasi-Experimental Research with Non-Equivalent Control Group Design. The samples was chosen by purposive-sampling which result the experimental class and the control class. The data analysis was t-test which showed t-count (2.77) $>$ t-table (1.67) and N-Gain test which showed the average N-Gain test of the experimental class was 0.762 which high category and the control class was 0.687 which medium category. Then it can be concluded that the use of ludo game based on Chemo-Edutainment for Atomic Structure effective to increase $10^{\text {th }}$ students achievement from SMA N 3 Padang.
\end{abstract}

\section{KEYWORDS}

Effectivity, ludo game, atomic structure, t-test, N-Gain, study result.

\section{ABSTRAK}

Penelitian ini bertujuan untuk menentukan tingkat efektivitas penggunaan media pembelajaran permainan ludo kimia berbasis Chemo-Edutainment pada materi Struktur Atom terhadap hasil belajar siswa kelas X SMA N 3 Padang. Jenis penelitian ini adalah Quasi-Experimental Research dengan rancangan Non-equivalent Control Group Design. Sampel dipilih dengan teknik Purposive-Sampling sehingga didapatkan kelas eksperimen dan kelas kontrol. Analisis data yang digunakan adalah uji-t dengan hasil t-hitung $(2,77)$ > t-tabel $(1,67)$ dan uji N-Gain dengan hasil rata-rata uji N-Gain dari kelas eksperimen adalah 0,762 dengan kategori tinggi dan kelas kontrol adalah 0,687 dengan kategori sedang. Maka dapat disimpulkan bahwa penggunaan media pembelajaran permainan ludo kimia berbasis Chemo-Edutainment pada materi Struktur Atom efektif meningkatkan hasil belajar siswa kelas $\mathrm{X}$ SMA N 3 Padang.

KATA KUNCI

Efektivitas, permainan ludo kimia, struktur atom, uji-t, N-Gain, hasil belajar. 


\section{PENDAHULUAN}

Materi struktur atom adalah salah satu materi yang sulit dipahami oleh siswa karena merupakan dasar untuk mempelajari materi sistem periodik unsur pada kelas X. Kendala dan hambatan yang dihadapi siswa dalam pembelajaran kimia pada materi struktur atom adalah dalam hal berfikir abstrak, karena siswa masih kesulitan menghubungkan antara struktur atom yang meliputi kulit, sub kulit, dan orbital yang dikaitkan dengan tingkat energi terhadap bilangan kuantum. Bahkan hubungan tersebut digunakan untuk menentukan konfigurasi elektron yang pada akhirnya siswa harus menentukan periode dan golongan pada sistem periodik berdasarkan bilangan kuantum ataupun konfigurasi elektron ${ }^{[1]}$. Berdasarkan hal tersebut diperlukan pengulangan (repetisi) dengan banyak membaca, berdiskusi dan pemantapan materi melalui pemberian latihan soal-soal bagi siswa. Pemberian latihan siswa berfungsi untuk memantapkan konsep materi yang merupakan kompetensi pengetahuan yang harus dicapai oleh $\operatorname{siswa}^{[2]}$.

Salah satu jenis latihan yang dapat diberikan kepada siswa adalah melalui media pembelajaran dalam bentuk permainan. Dengan menggunakan media pembelajaran diharapkan siswa menjadi lebih tertarik dan aktif dalam mempelajari kimia dan termotivasi untuk belajar ${ }^{[3]}$. Berdasarkan hasil pengisian angket yang dilakukan oleh guru kimia SMA N 3 Padang didapatkan bahwa pada pembelajaran struktur atom guru menggunakan media pembelajaran berupa modul dan power point. Untuk memantapkan konsep guru memberikan latihan kepada siswa yang berasal dari buku cetak dan bersifat individual. Hal ini menyebabkan rendahnya motivasi dan kurangnya partisipasi aktif siswa saat mengerjakan latihan yang tentu akan berdampak pada pemantapan konsep dan hasil belajar. Oleh karena itu diperlukan upaya untuk memantapkan konsep siswa agar hasil belajar menjadi lebih baik. Salah satu upaya yang dapat dilakukan adalah dengan menggunakan permainan sebagai media pembelajaran untuk latihan. Karena peserta didik yang berumur 7-18 tahun cenderung menyukai permainan dalam kegiatan pembelajaran ${ }^{[4]}$.

Penggunaan permainan sebagai media pembelajaran dapat meningkatkan hasil belajar siswa. Hal ini sesuai dengan penelitian bahwa setelah penerapan penggunaan permainan ular tangga sebagai media edutaiment dapat mencapai ketuntasan belajar pada materi Sistem Periodik Unsur kelas X SMAN 2 Tanah Putih ${ }^{[5]}$. Selanjutnya penggunaan media ludo word game sebagai media chemo edutainment pada materi ikatan kimia efektif meningkatkan hasil belajar peserta didik kelas X SMAN 16 Padang ${ }^{[6]}$. Serta penggunaan media permainan ular tangga kimia pada materi ikatan kimia memiliki tingkat efektifitas tinggi terhadap hasil belajar siswa kelas X SMAN 1 2x11 Kayu Tanam $^{[7]}$.
Berdasarkan uraian tersebut, saat ini telah tersedia media pembelajaran yang telah dikembangkan dalam bentuk permainan ludo kimia berbasis Chemo-Edutainment pada materi Struktur Atom ${ }^{[8]}$. Media ini telah diuji validitas dan praktikalitasnya dengan kategori yang sangat tinggi, namun belum diuji efektivitasnya terhadap hasil belajar siswa. Oleh karena itu peneliti tertarik melakukan penelitian tentang "Efektivitas Penggunaan Media Pembelajaran Permainan Ludo Kimia Berbasis Chemo-Edutainment Pada Materi Struktur Atom Terhadap Hasil Belajar Siswa Kelas X SMA N 3 Padang”.

\section{METODE}

Penelitian ini dilaksanakan di SMA N 3 Padang dengan jenis penelitian eksperimen semu (Quasi Experimental Research) dan rancangan penelitian Non-Equivalent Control Group Design yang dapat dilihat pada Tabel 1:

Tabel 1. Rancangan penelitian non-equivalent control group design ${ }^{[9]}$

\begin{tabular}{c|c|c|c} 
Kelas & Pretest & $\begin{array}{c}\text { Per- } \\
\text { lakuan }\end{array}$ & Postest \\
\hline Eksperimen & $\mathrm{O}_{1}$ & $\mathrm{X}$ & $\mathrm{O}_{3}$ \\
\hline Kontrol & $\mathrm{O}_{2}$ & - & $\mathrm{O}_{4}$
\end{tabular}

Keterangan :

$\mathrm{O}_{1}$ : Tes awal untuk kelas eksperimen

$\mathrm{O}_{2}$ : Tes awal untuk kelas kontrol

$\mathrm{O}_{3}$ : Tes akhir untuk kelas eksperimen

$\mathrm{O}_{4}$ : Tes akhir untuk kelas kontrol

$\mathrm{X}$ : Pembelajaran dengan menggunakan media permainan ludo kimia berbasis ChemoEdutainment

Populasi dalam penelitian ini adalah seluruh siswa kelas X MIPA di SMAN 3 Padang pada semester ganjil tahun ajaran 2019/2020. Sampel pada penelitian ini diambil dengan menggunakan teknik Purposive Sampling sehingga didapatkan kelas X MIPA 4 sebagai kelas eksperimen yang diberi perlakuan menggunakan media permainan ludo kimia berbasis Chemo-Edutainment dan kelas $\mathrm{X}$ MIPA 7 sebagai kelas kontrol yang tidak diberi perlakuan menggunakan media permainan ludo kimia berbasis Chemo-Edutainment.

Variabel yang digunakan pada penelitian ini adalah variabel bebas, variabel terikat dan variabel kontrol. a). Variabel independen/bebas, yaitu variabel yang mempengaruhi atau yang menjadi sebab perubahan/timbulnya variabel terikat. Pada penelitian ini yang menjadi variabel bebas adalah pembelajaran dibantu media permainan ludo kimia berbasis Chemo-Edutainment pada kelas eksperimen dan pembelajaran seperti biasa pada kelas kontrol. b). Variabel dependen/terikat, yaitu variabel yang dipengaruhi atau yang menjadi akibat, karena adanya variabel bebas. Pada penelitian ini yang menjadi variabel terikat adalah hasil belajar siswa yang diperoleh dari hasil pretest dan posstest pada 
kelas eksperimen dan kelas kontrol. c). Variabel kontrol, yaitu variabel yang dikendalikan atau dibuat konstan sehingga pengaruh variabel bebas terhadap variabel terikat tidak dipengaruhi oleh faktor luar yang tidak diteliti. Pada penelitian ini yang menjadi variabel kontrol semuanya haruslah dibuat sama diantaranya kemampuan awal siswa, materi, buku sumber dan alokasi waktu, guru yang mengajar, serta jenis dan jumlah soal yang diujikan.

Data yang digunakan dalam penelitian ini adalah data primer yang diperoleh dari hasil belajar siswa melalui tes tertulis diawal dan di akhir pembelajaran. Sumber data dalam penelitian ini adalah siswa pada kelas eksperimen dan kelas kontrol.

\section{HASIL DAN DISKUSI}

\subsection{Hasil Belajar}

Berdasarkan penelitian yang telah dilakukan di SMA N 3 Padang diperoleh hasil belajar siswa pada kompetensi kognitif. Tes awal (pretest) bertujuan untuk mengetahui kemampuan awal siswa. Secara ringkas hasil pretest siswa pada kelas eksperimen dan kelas kontrol dapat dilihat pada Tabel 2.

Tabel 2. Rata-Rata Pretest Kelas Eksperimen dan Kelas Kontrol

\begin{tabular}{c|c|c} 
Kelas & Jumlah Siswa & $\begin{array}{c}\text { Rata-Rata } \\
\text { Pretest }\end{array}$ \\
\hline Eksperimen & 36 & 37,33 \\
\hline $\begin{array}{c}\text { Kontrol } \\
\text { Setelah diberikan pretest, }\end{array}$ & $\begin{array}{c}36,11 \\
\text { dilakukanlah }\end{array}$
\end{tabular}
pembelajaran mengenai materi Struktur Atom pada kelas eksperimen dan kelas kontrol. Tes akhir (posttest) diberikan diakhir proses pembelajaran yang bertujuan untuk mengetahui hasil belajar siswa setelah diberi perlakuan. Secara ringkas ratarata posttest siswa pada kelas eksperimen dan kelas kontrol dapat dilihat pada Tabel 3.

Tabel 3. Rata-Rata Posttest Kelas Eksperimen dan Kelas Kontrol

\begin{tabular}{c|c|c} 
Kelas & Jumlah Siswa & $\begin{array}{c}\text { Rata-Rata } \\
\text { Posttest }\end{array}$ \\
\hline Eksperimen & 36 & 85,67 \\
\hline Kontrol & 36 & 80
\end{tabular}

Hasil belajar siswa pada kelas eksperimen dan kelas kontrol sebelum diberi perlakuan pada Tabel 2 menunjukkan kemampuan awal siswa, dimana ratarata kelas eksperimen adalah 37,33 dan rata-rata kelas kontrol adalah 35,11. Nilai rata-rata pretest menunjukkan bahwa kedua kelas sampel memiliki kemampuan awal yang sama. Kemampuan awal yang sama merupakan variabel yang harus dikontrol peneliti dalam penelitian ini.

Tes akhir (posttest) dilakukan untuk mengetahui hasil belajar siswa setelah diberi perlakuan. Nilai posttest pada masing-masing kelas eksperimen dan kelas kontrol dapat dilihat pada Tabel 3, dimana rata-rata nilai posttest kelas eksperimen adalah 85,67 dan kelas kontrol adalah 80. Hal ini dikarenakan dalam pemantapan konsep di kelas eksperimen siswa mengerjakan soal-soal latihan pada permainan edukatif ludo kimia berbasis Chemo-Edutainment sehingga siswa berpartisipasi dan termotivasi dalam belajar. Dengan menggunakan permainan setiap siswa akan berlomba untuk memenangkan permainan sehingga siswa terlibat penuh dalam proses pembelajaran ${ }^{[10]}$. Berbeda dengan kelas kontrol, untuk memantapkan konsep siswa tidak mengerjakan latihan berupa permainan edukatif ludo kimia berbasis ChemoEdutainment dan tidak dimanfaatkan dengan baik karena umumnya siswa kurang berpartisipasi jika dihadapkan dengan soal-soal.

\subsection{Analisis Data}

Data yang diperoleh dari nilai pretest dan posttest diolah dan dianalisis untuk menarik kesimpulan. Sebelum analisis data kemampuan awal siswa (pretest) dan hasil belajar siswa (posttest) dari kelas eksperimen dan kelas kontrol diuji terlebih dahulu normalitas dan homogenitasnya. Selanjutnya dilakukan teknik analisis data pada penelitian ini yaitu uji kesamaan dua rata-rata (t-test) untuk mengetahui perbedaan hasil belajar antara kelas eksperimen dan kontrol, uji $\mathrm{N}$-Gain untuk mengetahui peningkatan pemahaman sebelum dan sesudah pembelajaran dan persentase ketuntasan belajar untuk mengetahui berapa persen siswa yang mencapai nilai di atas kriteria ketuntasan minimal.

\subsubsection{Uji Normalitas}

Uji normalitas menggunakan uji Liliefors dengan kriteria pengambilan keputusasan bila L0 < Lt pada taraf nyata $\alpha=0,05$. Berdasarkan hasil pretest diperoleh uji normalitas kelas eksperimen dan kelas kontrol seperti terlihat pada Tabel 4 .

Tabel 4. Hasil Uji Normalitas Pretest Kelas Eksperimen dan Kelas Kontrol

\begin{tabular}{c|c|c|c|c|c} 
Kelas & A & $\mathbf{N}$ & Lo & Lt & $\begin{array}{c}\text { Kete- } \\
\text { rangan }\end{array}$ \\
\hline $\begin{array}{c}\text { Eksperi- } \\
\text { men }\end{array}$ & 0,05 & 36 & 0,09 & 0,147 & $\begin{array}{c}\text { Terdis- } \\
\text { tribusi } \\
\text { Normal }\end{array}$ \\
\hline $\begin{array}{c}\text { Kontrol } \\
\text { Selaj }\end{array}$ & 0,05 & 36 & 0,105 & 0,147 & norme
\end{tabular}

eksperimen dan kelas kontrol dapat dilihat pada Tabel 5.

Tabel 5. Hasil Uji Normalitas Posttest Kelas Eksperimen dan Kelas Kontrol 


\begin{tabular}{c|c|c|c|c|c} 
Kelas & $\mathbf{A}$ & $\mathbf{N}$ & Lo & Lt & $\begin{array}{c}\text { Ket- } \\
\text { eran- } \\
\text { gan }\end{array}$ \\
\hline Eksperimen & 0,05 & 36 & 0,113 & 0,147 & $\begin{array}{c}\text { Terdis- } \\
\text { tribusi } \\
\text { Normal }\end{array}$ \\
\hline Kontrol & 0,05 & 36 & 0,110 & 0,147 &
\end{tabular}

\subsubsection{Uji Homogenitas}

Uji homogenitas dilakukan menggunakan uji $\mathrm{F}$ dengan kriteria pengambilan keputusan bila $\mathrm{F}_{\text {hitung }}<$ $F_{\text {tabel }}$ pada taraf nyata $\alpha=0,05$. Hasil uji homogenitas pretest kedua kelas eksperimen dan kelas kontrol dapat dilihat pada Tabel 6.

Tabel 6. Hasil Uji Homogenitas Pretest Kelas Eksperimen dan Kelas Kontrol

\begin{tabular}{c|c|c|c|c|c} 
Kelas & $\mathbf{S}^{2}$ & $\mathbf{N}$ & $\mathbf{F}_{\text {hitung }}$ & $\mathbf{F}_{\text {tabel }}$ & $\begin{array}{c}\text { Keteran- } \\
\mathbf{g a n}\end{array}$ \\
\hline $\begin{array}{c}\text { Eksperi- } \\
\text { men }\end{array}$ & 69,82 & 36 & \multirow{2}{*}{16} & 1,84 & Homogen \\
\hline Kontrol & 81,37 & 36 & & &
\end{tabular}

Selanjutnya hasil uji homogenitas posttest kelas eksperimen dan kelas kontrol dapat dilihat pada Tabel 7.

Tabel 7. Hasil Uji Homogenitas Posttest Kelas Eksperimen dan Kelas Kontrol

\begin{tabular}{c|c|c|c|c|c} 
Kelas & $\mathbf{S}^{2}$ & $\mathbf{N}$ & $\mathbf{F}_{\text {hitung }}$ & $\mathbf{F}_{\text {tabel }}$ & $\begin{array}{c}\text { Keteran- } \\
\text { gan }\end{array}$ \\
\hline $\begin{array}{c}\text { Eksperi- } \\
\text { men }\end{array}$ & 69,82 & 36 & \multirow{2}{*}{16} & 1,84 & Homogen \\
\hline Kontrol & 81,37 & 36 & & &
\end{tabular}

\subsubsection{Uji Hipotesis (Uji-t)}

Berdasarkan hasil analisis uji normalitas dan analisis uji homogenitas kelas eksperimen dan kelas kontrol menunjukkan bahwa data kemampuan awal dan hasil belajar terdistribusi normal dan mempunyai varians yang homogen. Oleh karena itu untuk menguji hipotesis dilakukan uji kesamaan dua rata-rata (uji-t) dengan hipotesis statistik yaitu:

Keterangan :

$$
\begin{gathered}
\mathrm{H}_{0}: \mu_{1}=\mu_{2} \\
\mathrm{H}_{1}: \mu_{1}>\mu_{2}
\end{gathered}
$$

$\mu_{1}=$ rata-rata nilai kelas eksperimen

$\mu_{2}=$ rata-rata nilai kelas kontrol

Kriteria pengambilan keputusan adalah pada taraf nyata $\alpha=0,05$ terima $\mathrm{H}_{0}$ jika $\mathrm{t}_{\text {hitung }}<\mathrm{t}_{\text {tabel }}$ dimana $\mathrm{t}_{\text {tabel }}$ didapat dari daftar distribusi t dengan $\mathrm{dk}=\left(n_{1}+\right.$ $\left.n_{2}-2\right)$ dan peluang $(1-\alpha)$. Berdasarkan hasil analisis data diperoleh uji hipotesis terhadap kemampuan awal siswa (pretest) yang dapat dilihat pada Tabel 8 .

Tabel 8. Hasil Uji Hipotesis Pretest Kelas Eksperimen dan Kelas Kontrol

\begin{tabular}{c|c|c|c|c|c} 
Kelas & $\mathbf{N}$ & $\bar{X}$ & $\mathbf{S}^{2}$ & $\mathbf{t}_{\text {hitung }}$ & $\mathbf{t}_{\text {tabel }}$ \\
\hline $\begin{array}{c}\text { Eksperi- } \\
\text { men }\end{array}$ & 36 & 37,33 & 97,82 & \multirow{2}{*}{1,037} & 1,67 \\
\hline Kontrol & 36 & 35,11 & 83,30 & &
\end{tabular}

Tabel 8 menunjukkan bahwa nilai $t_{\text {hitung }}<t_{\text {tabel, }}$ maka $\mathrm{H}_{0}$ diterima. Hal ini menunjukkan bahwa tidak terdapat perbedaan hasil belajar antara kelas eksperimen dan kelas kontrol.

Selanjutnya uji hipotesis terhadap hasil belajar siswa (posttest) yang dapat dilihat pada Tabel 9.

Tabel 9. Hasil Uji Hipotesis Posttest Kelas Eksperimen dan Kelas Kontrol

\begin{tabular}{c|c|c|c|c|c} 
Kelas & $\mathbf{N}$ & $\bar{X}$ & $\mathbf{S}^{2}$ & $\mathbf{t}_{\text {hitung }}$ & $\mathbf{t}_{\text {tabel }}$ \\
\hline $\begin{array}{c}\text { Eksperi- } \\
\text { men }\end{array}$ & 36 & 85,67 & 69,82 & 2,77 & 1,67 \\
\hline Kontrol & 36 & 80 & 81,37 & &
\end{tabular}

Tabel 9 menunjukkan bahwa nilai $t_{\text {hitung }}>$ $t_{\text {tabel, }}$ maka $\mathrm{H}_{0}$ ditolak. Hal ini menunjukkan bahwa terdapat perbedaan hasil belajar kelas eksperimen dan kelas kontrol, dimana hasil belajar kelas eksperimen lebih tinggi dibandingkan hasil belajar kelas kontrol.

Adapun mengenai penolakan $\mathrm{H}_{0}$ dapat pula dilihat dari kurva daerah penerimaan dan penolakan $\mathrm{H}_{0}$ pada Gambar 1 .

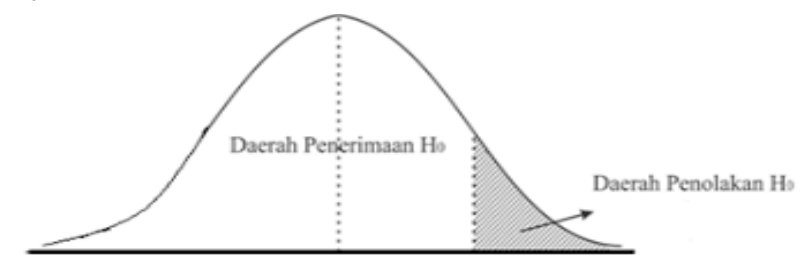

Gambar 1. Kurva Daerah Penerimaan dan Penolakan $\mathrm{H}_{0}$

\subsubsection{Uji N-Gain}

Uji N-Gain bertujuan untuk mengetahui peningkatan yang terjadi sebelum dan sesudah pembelajaran berdasarkan nilai pretest dan posttest pada kelas eksperimen dan kelas kontrol. Hasil ratarata uji N-Gain dapat dilihat pada Tabel 10.
Tabel 10. Hasil Uji N-Gain Kelas Eksperimen dan Kelas Kontrol

\begin{tabular}{c|c|c} 
Kelas & $\begin{array}{c}\text { Rata-Rata } \\
\text { N-Gain }\end{array}$ & Kategori \\
\hline Eksperimen & 0,763 & Tinggi \\
\hline
\end{tabular}




\begin{tabular}{c|c|c} 
Kelas & $\begin{array}{c}\text { Rata-Rata } \\
\text { N-Gain }\end{array}$ & Kategori \\
\hline Kontrol & 0,687 & Sedang
\end{tabular}

Berdasarkan data yang ada pada Tabel 10, kelas eksperimen memiliki rata-rata $\mathrm{N}$-Gain sebesar 0,762 dengan kategori tinggi dibandingkan dengan kelas kontrol yang memiliki rata-rata $\mathrm{N}$-Gain sebesar 0,687 dengan kategori sedang. Hal ini menunjukkan bahwa terjadi peningkatan hasil belajar kognitif siswa pada kelas eksperimen yang menggunakan permainan ludo kimia berbasis Chemo-Edutainment lebih baik daripada kelas kontrol.

\subsubsection{Persentase Ketuntasan Belajar}

Perbedaan hasil belajar siswa pada kelas eksperimen dan kelas kontrol juga dapat dilihat dari persentase ketuntasan belajar. Persentase ketuntasan digunakan untuk mengetahui ketuntasan hasil belajar siswa pada kedua kelas sampel terhadap penggunaan media permainan ludo kimia berbasis Chemo-Edutainment. Berdasarkan nilai KKM di SMA N 3 Padang yaitu 80, sehingga persentase ketuntasan belajar kelas sampel dapat dilihat pada Tabel 11.

Tabel 11. Persentase Ketuntasan Belajar Kelas Eksprimen dan Kelas Kontrol

\begin{tabular}{c|c|c|c} 
Kelas & $\begin{array}{c}\text { Jumlah } \\
\text { Siswa }\end{array}$ & $\begin{array}{c}\text { Jumlah } \\
\text { Siswa Yang } \\
\text { Tuntas }\end{array}$ & $\begin{array}{c}\text { Persentase } \\
\text { Ketuntasan } \\
\text { Belajar }\end{array}$ \\
\hline $\begin{array}{c}\text { Eksperi- } \\
\text { men }\end{array}$ & 36 & 29 & $80,56 \%$ \\
\hline $\begin{array}{c}\text { Kontrol } \\
\text { B. }\end{array}$ & 36 & 22 & $61,11 \%$
\end{tabular}

Pada Tabel 11 dapat dilihat bahwa kelas eksperimen jumlah siswa yang tuntas setelah diberikan posttest adalah 29 orang sehingga persentase ketuntasan belajar sebesar 80,56\% dengan kategori sangat baik, sedangkan pada kelas kontrol jumlah siswa yang tuntas adalah 22 orang sehingga persentase ketuntasan belajar sebesar 61,11\% dengan kategori cukup.

\section{SIMPULAN}

Berdasarkan hasil penelitian dapat ditarik kesimpulan bahwa penggunaan media pembelajaran permainan ludo kimia berbasis Chemo-Edutainment pada materi struktur atom efektif meningkatkan hasil belajar siswa kelas X SMA N 3 Padang. Hal ini terlihat dari perbedaan hasil belajar yang diperoleh kelas eksperimen $(85,67)$ lebih tinggi dibandingkan kelas kontrol (80), serta didukung oleh analisis uji-t yang memperoleh $t_{\text {hitung }}(2,77)>t_{\text {tabel }}(1,67)$. Selain itu, berdasarkan hasil uji N-Gain dapat diketahui bahwa peningkatan pemahaman kelas eksperimen memiliki rata-rata $\mathrm{N}-\mathrm{Gain}(0,762)$ dengan kategori tinggi daripada kelas kontrol $(0,687)$ dengan kategori sedang. Selanjutnya juga didukung oleh persentase ketuntasan belajar kelas eksperimen yaitu $(80,56 \%)$ yang lebih tinggi dari kelas kontrol $(61,11 \%)$.

\section{REFERENSI}

1. M. Tohir. 2018. Penggunaan Tabel Mt Kuantum Untuk Meningkatkan Hasil Belajar Siswa Pada Materi Struktur Atom Dan Sistem Periodik Di Kelas X Mipa 5 SMAN 1 Tanjungpinang. Jurnal Zarah, Vol. 6 No. $1,6-12$

2. Hamalik, O.2008. Kurikulum Dan Pembelajaran. Jakarta: Bumi Aksara.

3. Sanjaya, W. 2012. Media Komunikasi Pembelajaran. Jakarta: Kencana Prenada Media Group.

4. UNESCO. 1988. Games Toys in The Teaching of Science and Technology. Paris: Division of Science Technical and Enviromental Education.

5. Sufyanto., L. R. \& Herdin.2014. Penggunaan Permainan Ular Tangga Sebagai Media Chemo Edutaiment Untuk Mencapai Ketuntasan Belajar Peserta Didik Pada Sub pokok Bahasan Sistem Periodik Unsur Di Kelas X SMAN 2 Tanah Putih. Jurnal Pendidikan Kimia, p. Pekanbaru: FKIP Universitas Riau.

6. Niken, G. \& Fauzana, G.2019. Efektivitas Ludo Word Game (LWG) Sebagai Media Chemo Edutainment untuk Meningkatkan Hasil Belajar Peserta Didik Pada Materi Ikatan Kimia di Kelas X SMAN 16 Padang. Ranah Research, 3(13), pp. 18-25.

7. Maulidina, Y. \& Iswendi.2019. Efektivitas Penggunaan Permainan Ular Tangga Kimia Pada Materi Ikatan Kimia Terhadap Hasil Belajar Siswa Kelas X SMA/MA. Ranah Research, Volume 3, pp. 165-170.

8. Munif, Adli Hadiyan. 2018. Pengembangan Permainan Ludo Kimia Berbasis ChemoEdutainment (CET) Sebagai Media Pembelajaran Pada Materi Struktur Atom Kelas X SMA/MA. Skripsi. Pendidkan Kimia Universitas Negeri Padang

9. Sugiyono. 2013. Metode Penelitian Kombinasi. Bandung: Alfabeta.

10. Yusuf, Y. \& Auliya, U. 2011. Sirkuit Pintar: Melejitkan Kemampuan Matematika \& Bahasa Inggris dengan Metode Ular Tangga. Jakarta: Visimedia. 